\title{
Development and Tests of a Flexible Superconducting Bus-Line for the Large Helical Device
}

\author{
Toshiyuki Mito, Shuichi Yamada, Kazuya Takahata, Nagato Yanagi, Hirotaka Chikaraishi, Arata Nishimura, \\ Shugo Tanahashi, Osamu Motojima, Junya Yamamoto \\ National Institute for Fusion Science (NIFS), 322-6 Oroshi, Toki, Gifu 509-52, Japan
}

Toshio Uede, Hisaaki Hiue, Kazuo Ueda, Ikuo Itoh

Fuji Electric Co. Ltd., Kawasaki 210, Japan

Masaru Ikeda, Itaru Inoue

Furukawa Electric Co. Ltd., Tokyo 100, Japan

\begin{abstract}
A flexible superconducting bus-line is proposed as an electrical feeder between the superconducting coils of the Large Helical Device (LHD) and the device's power supplies. The bus-line consists of superconducting cables and a cryogenic flexible transfer-line. A specially developed aluminum stabilized $\mathrm{NbTi} / \mathrm{Cu}$ compacted strand cable satisfies requirements for large current capacity, high stability, high reliability and flexibility. A full-scale model with a length of $20 \mathrm{~m}$ was designed and constructed to investigate the feasibility and performance of the superconducting bus-line. Its fabrication, transportation, installation, cooling and excitation tests were successfully carried out. The bus-line was very stable and could be excited up to $40 \mathrm{kA}$ (rated current is $30 \mathrm{kA}$ ) without a quench. The stability, current distribution, heat load were also measured.
\end{abstract}

\section{INTRODUCTION}

A large superconducting coil system such as the Large Helical Device (LHD) | 1 | requires long electrical feeders with large current capacity to connect coils and the power supplies which are installed apart from them. A feeder usually consists of water-cooled bus bars and current leads. The water-cooled bus-bar needs a large cross-sectional area $\left(250 \mathrm{~mm}^{2}\right.$ per $\left.1 \mathrm{kA}\right)$ and the current leads require large cryostats and cryogenic piping, including valves and other auxiliary equipment. It is difficult to install large current-lead cryostats and to connect water-cooled bus bars near the superconducting coils. The electrical feeder is one of the important parts of the superconducting coil system because stored energy must be extracted safely through it when the coils quench. Therefore, the feeder must be designed and constructed carefully. A flexible superconducting bus-line is examined here as a possible solution to this problem. In addition, using a superconducting bus-line allows electric power consumption and operating costs to be reduced.

\section{DESIGN OF SUPERCONDUCTING BUS-LINE}

The basic design conditions for a flexible superconducting bus-line are as follows [2].

(1) The bus-line consists of a flexible cryogenic transferline and flexible superconducting cables.

Manuscript received September 20, 1993.
(2) A pair of $+/$ - superconducting cables is placed in the innermost channel of a flexible transfer-line and is cooled by a forced-flow of two-phase helium to satisfy cryogenic stability requirements.

(3) Most parts of the superconducting bus-line are assembled at the factory, to eliminate site assembly work.

A comparison of specifications for a bus-line proposed for LHD and a bus-line for a full-scale model is shown in Table 1. The overall configuration of the conceptual design for the bus-line is shown in Fig. 1. A full-scale model was fabricated based on this configuration. The effective. length of the full scale model is $20 \mathrm{~m}$, which is about $1 / 3$ of that of the flexible superconducting bus-line for LHD.

The configuration of the superconducting cable for the superconducting bus-line is shown in Fig. 2, and its basic parameters are listed in Table 2 . An aluminum stabilized $\mathrm{NbTi} / \mathrm{Cu}$ compacted strand cable has been newly developed to satisfy the high stability and flexibility requirements of a superconducting bus-line.

The vacuum insulated transfer-line consists of four corrugated tubes assembled coaxially. Two-phase helium flows

TABLE 1

SPECIFICATIONS OF BUS-LINES FOR LHD AND FULL SCALE MODEL

\begin{tabular}{|c|c|c|c|}
\hline & & $\begin{array}{c}\text { For LHD } \\
\text { (updated design) } \\
\end{array}$ & $\begin{array}{c}\text { Full scalc } \\
\text { model }\end{array}$ \\
\hline 1. & Rated current & $13 \mathrm{kA}-31 \mathrm{kA}$ & $30 \mathrm{kA}$ \\
\hline 2. & $\begin{array}{l}\text { Breakdown vollage (in } \\
\text { helium gas at } 1 \mathrm{~atm}, 77 \mathrm{~K} \text { ) }\end{array}$ & $\begin{array}{l}\text { for Poloidal coil } \\
\text { DC } 5 \mathrm{kV} \\
\text { for Helical coil } \\
\text { DC } 2 \mathrm{kV}\end{array}$ & $\begin{array}{c}\text { DC } 2 \mathrm{kV} \\
\text { (design) } \\
>\text { DC } 5 \mathrm{kV} \\
\text { (measured) }\end{array}$ \\
\hline 3. & Length & $45 m-65 m$ & $20 \mathrm{~m}$ \\
\hline 4. & Conductor & \multicolumn{2}{|c|}{$\begin{array}{c}\text { Aluminum stabilized } \mathrm{NbTi} / \mathrm{Cu} \\
\text { compacted strand cable }\end{array}$} \\
\hline 5. & Minimum bending radius & $1.5 \mathrm{~m}$ & $1.5 \mathrm{~m}$ \\
\hline 6. & Transfer-line & $\begin{array}{l}\text { Coaxial five-channel } \\
\text { with } 80 \mathrm{~K} \text { sthield }\end{array}$ & $\begin{array}{l}\text { Four- } \\
\text { channel }\end{array}$ \\
\hline 7. & Outer diameter & $<0.25 \mathrm{~m}$ & $0.22 \mathrm{~m}$ \\
\hline 8. & Cooling method & \multicolumn{2}{|c|}{ Forced-flow ol two-phase helium } \\
\hline 9. & Heat load & & \\
\hline & Liquid helium channe] & $<0.2 \mathrm{~W} / \mathrm{m}$ & $<0.3 \mathrm{~W} / \mathrm{m}$ \\
\hline & Relurning gas channel & $<0.2 \mathrm{~W} / \mathrm{m}$ & $<3.5 \mathrm{~W} / \mathrm{m}$ \\
\hline & $80 \mathrm{~K}$ shicld gas channel & $<3 \mathrm{~W} / \mathrm{m}$ & - \\
\hline
\end{tabular}




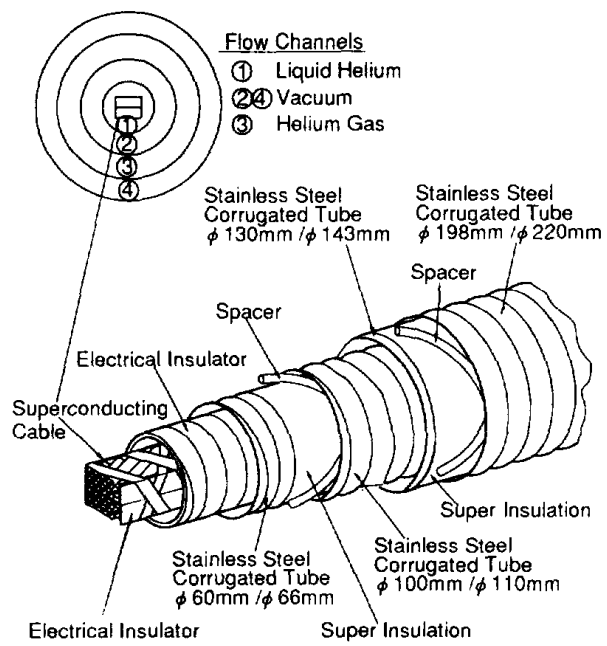

Fig. 1. Configuration of a flexible superconducting bus-line

through the innermost channel and the returned gas helium flows through an outer annular channel as a thermal shield. A further reduction of the thermal load is currently under consideration. A change from the present four-channel transfer-line to a five-channel transfer-line with a $80 \mathrm{~K}$ thermal shield is being examined as one possible way for performing this.

\section{FABRICATION AND INSTALLATION OF FULL-SCALE MODEL}

An important feature of this bus-line is that its fabrication is almost wholly performed in the manufacturer's shop. Only laying of bus-lines and terminal mounting, including piping connections, are performed on site. Fabrication reliability is enhanced and trouble related to field work is minimized when fabrication and installation are done like this. The transportation of the bus-line from the factory to the site, however, must be considered carefully. There are legal height, width and other limits and restrictions on road freight in Japan.

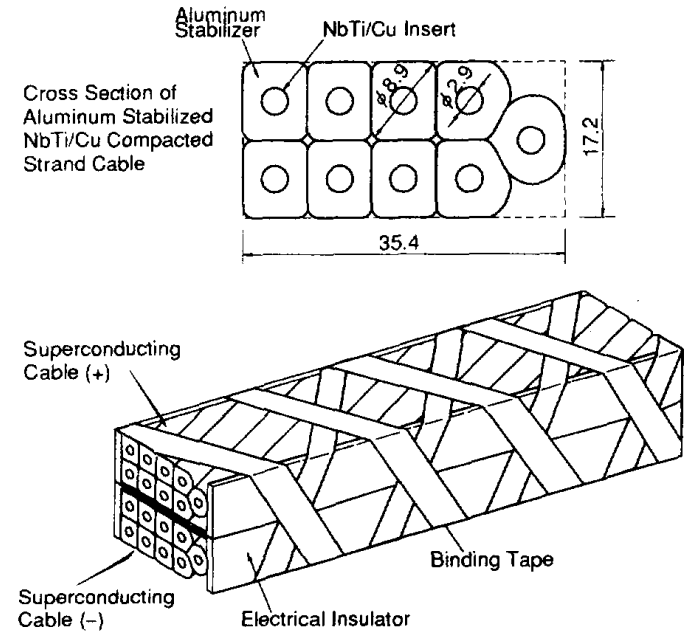

Fig. 2. An aluminum stabilized $\mathrm{NbTi/Cu}$ compacted strand cable for the supcrconducting bus-line.
TABL.E 2

PARAMETERS OF SUPERCONDUICTING CABLE FOR BUS-LINE

\begin{tabular}{lll}
\hline \multicolumn{3}{c}{ Aluminum Slabilized, Compacted Strand Cable } \\
\hline 1. & Rated current & $30 \mathrm{kA}$ at $1 \mathrm{~T}, 4.2 \mathrm{~K}$ \\
2. & Critical current & $180 \mathrm{kA}$ at $1 \mathrm{~T}, 4.2 \mathrm{~K}$ \\
3. & Size & $17.2 \mathrm{~mm} \times 35.4 \mathrm{~mm}$ \\
4. & Number of strands & 9 \\
5. & Twist pitch of strands & $374 \mathrm{~mm}$ \\
6. & Electrical Insulation & Polyamide paper (nomex) \\
7. & Al sectional area & $5(X) \mathrm{mm}^{2}$ \\
8. & Cooling ratio & $13 \%$ of the cable surface \\
9. & Minimum propagation current & $40 \mathrm{kA}$ \\
\hline & & Superconducting Sirand \\
\hline 1. & Outcr diameler & $8.95 \mathrm{~mm}$ \\
2. & NbTi/Cu insert diameter & $2.91 \mathrm{~mm}$ \\
3. & Al:Cu:NbTi ratio & $8.4: 0.5: 0.5$ \\
4. & Twist pitch of filanents & $60 \mathrm{~mm}$ \\
5. & Filament diameter & $30 \mu \mathrm{m}$ \\
6. & NbTi/Cu critical current densily & $6000 \mathrm{~A} / \mathrm{mm}^{2}$ at $1 \mathrm{~T}, 4.2 \mathrm{~K}$ \\
7. & Al resistivity & $3 \times 10^{-11} \Omega \mathrm{m}$ at $1 \mathrm{~T}, 4.2 \mathrm{~K}$ \\
\hline
\end{tabular}

The principal measures taken to satisfy transportation requirements were to reduce the allowable bending radius of a transfer-line to $1.5 \mathrm{~m}$ and to reduce the dimensions of the terminal structure. The structures of the terminals on the short-circuit sides of the full-scale model are shown in Fig. 3.

Fig. 4 shows the installation work done at the experimental site. During installation of the full-scale model, we had to bend the transfer-line up to $1.5 \mathrm{~m}$ (vertically, horizontally and obliquely) several times because of severe site restrictions. This experience was very valuable, and is applicable to the installation of bus-lines for LHD.

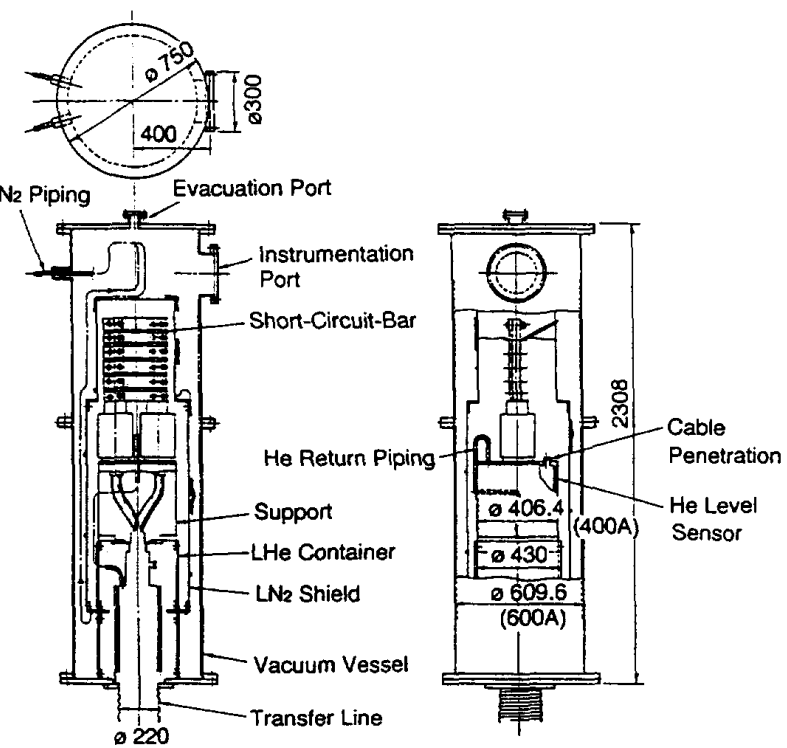

Fig. 3. The structure of the 1erminal on the short-circuit side of the fullscale model. 


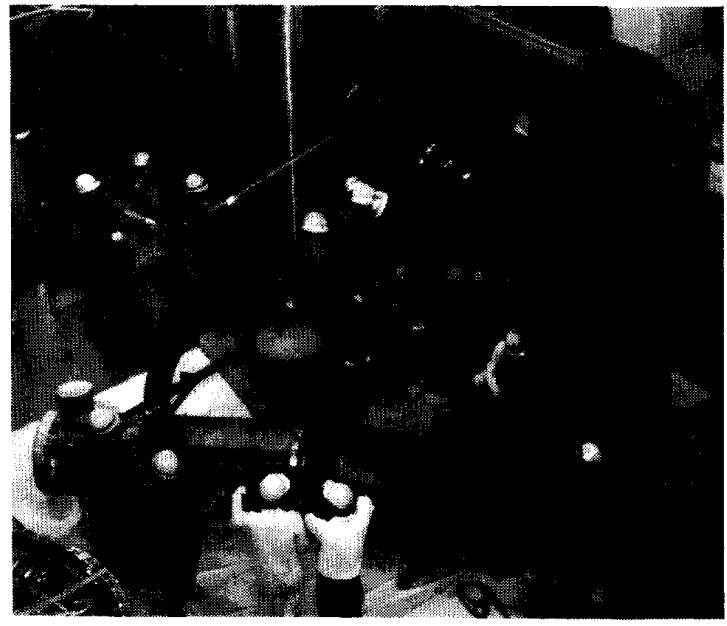

Fig. 4. Installation work of the full scale model at the experimental site.

\section{COOLING AND EXCITATION TESTS OF FULL-SCALE MODEL}

\section{A. Measuring Points}

Fig. 5 shows measuring points of the full-scale model. Many kinds of sensors (temperature sensors, pressure gauges, flow meters, liquid helium level meters, voltage taps, heaters) were installed in order to investigate the operability of the bus-line, the thermal characteristics of the transfer-line and the stability of the superconducting cable. Especially, the characteristics of the initial current distribution among nine strands and the re-distribution after partial normal transition are considered as important test items. Because the aluminum surface of the strand was naturally oxidized and it might become a barrier to the current transfer. We installed Rogowski coils for each strand of the superconducting cable $(+)$ at both terminals (the current lead side and the short-circuit side) to measure the current distribution among the nine-strand cable.

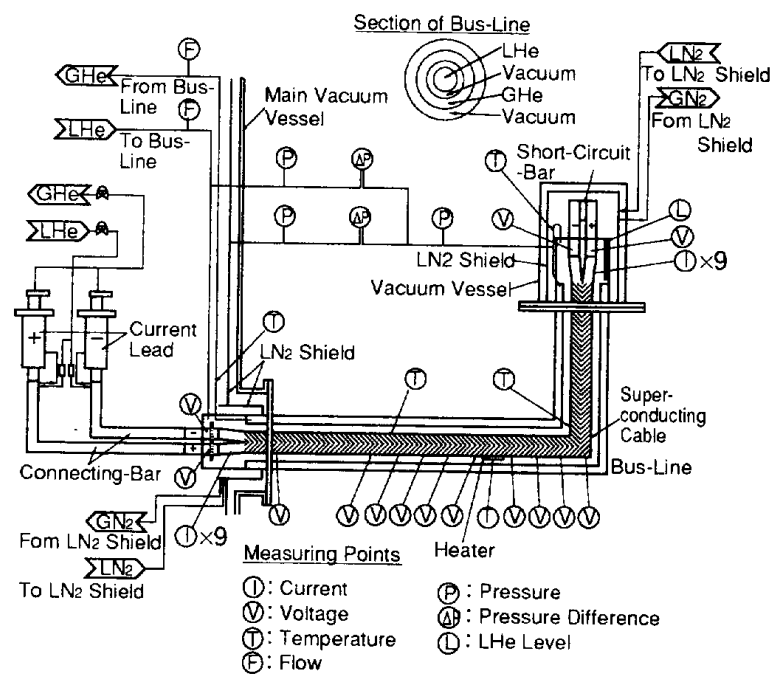

Fig. 5. Measuring points of the full-scale model
Two kinds of heaters ( $\mathrm{H} /$ and $\mathrm{H} 2$ ) were placed on the cable at the center of the bus-line. $\mathrm{H} 1$ is a resistive film heater attached to one strand of the nine-strand cable to investigate characteristics of the current re-distribution after one strand becomes normal. $\mathrm{H} 2$ is a stainless-steel foil heater which covers a flat surface of the cable to measure the stability margin and the minimum propagation current.

\section{B. Cooling and Excitation Tests}

The full-scale model was cooled down from the room temperature to the liquid helium temperature within 24 hours by using a helium refrigerator with the capacity of $600 \mathrm{~W}$ at 4.4 K. We used a test cryostat for supercritical helium (SHE) forced-flow cooled coils and a SHE heat exchanger unit, reducing helium pressure, to replace a forced flow system of two-phase helium. Therefore, the temperature and pressure of two-phase helium were relatively high $(4.5-4.7 \mathrm{~K}$ and 135 $155 \mathrm{kPa}$, respectively) during the excitation tests. The flow rate of two-phase helium was kept constant in $11-12 \mathrm{~g} / \mathrm{s}$.

The full-scale model was successfully excited up to $40 \mathrm{kA}$, over the rated current of $30 \mathrm{kA}$, without a quench. No voltage spike signal and no normal transition were observed during the excitation.

\section{Measurement of Stability}

We measured the stability margin and the minimum propagation current of the full-scale model using the heater $\mathrm{H} 2$. The input signal of the heater was a rectangular pulse with the time duration of $1 \mathrm{~s}$. By keeping the transport current at a constant value, we increased the heater input energy step by step. Fig. 6 shows the heater input energy required to initiate a quench versus the transport current. Below the heat input energy of $40 \mathrm{~J}$, no normal transition was observed regardless of the transport current $(30 \mathrm{kA}-35$ $\mathrm{kA})$. Below the current of $32.5 \mathrm{kA}$, the initiated normal zone recovered up to the maximum heat input energy $(80 \mathrm{~J})$. Therefore, the minimum propagation current of the full-scale model was larger than $32.5 \mathrm{kA}$. The bus-line was fully stable at the rated current of $30 \mathrm{kA}$.

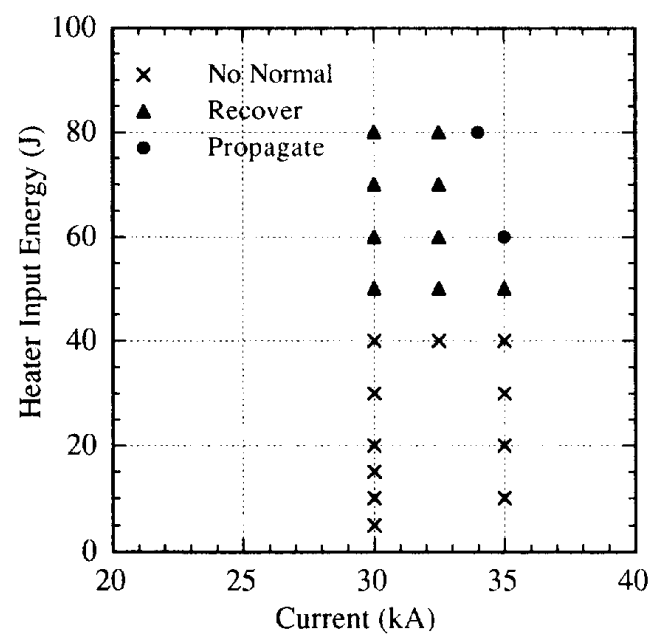

Fig. 6. Heater input energy required to initiate a quench versus the transport current. 


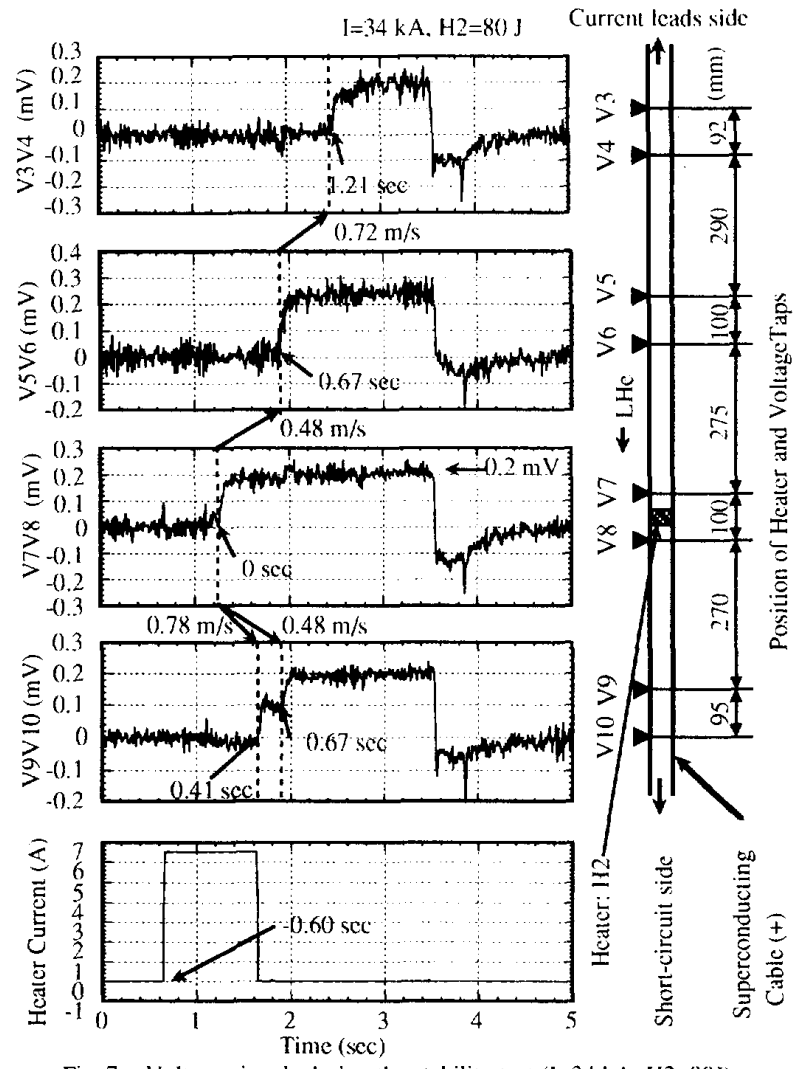

Fig. 7. Voltage signals during the slabilily $1 \mathrm{csl}(\mathrm{I}=34 \mathrm{kA}, \mathrm{H} 2=80 \mathrm{~J})$.

Fig. 7 shows the observed voltage signals near the heater $\mathrm{H} 2$ during the stability test at the current of $34 \mathrm{kA}$ and the heater input energy of $80 \mathrm{~J}$. The measured normal propagation velocity was very small; $0.48-0.78 \mathrm{~m} / \mathrm{s}$. The resistance of the cable after the normal transition was measured to be $5.9 \times 10^{-8} \Omega / \mathrm{m}$. This leads to the aluminum resistivity about $3 \times 10^{-11} \Omega \mathrm{m}$, being close to the design value.

\section{Measurement of Current Distribution}

The current re-distribution after one strand became normal was measured at the current of $35 \mathrm{kA}$ using the heater $\mathrm{H} 1$. The method of the heat input was the same as that of the heater $\mathrm{H} 2$ described above. For heater input energy below 15 $\mathrm{J}$, no normal transition was observed. Between $20 \mathrm{~J}$ and $35 \mathrm{~J}$, a small normal region was observed which shrank after the end of the heater input. However, no signal was observed in Rogowski coils, which were installed for each strand at both end terminals, during the current transfer from the strand being in normal state to other strands. This means that the current re-distribution can occur locally near the normal region. We could not make all strands quenching because the heater $\mathrm{H} 1$ burned out during the heat input of $40 \mathrm{~J}$.

We also measured the current distribution during the rampup of the transport current with the ramp rate from $100 \mathrm{~A} / \mathrm{s}$ to $2 \mathrm{kA} / \mathrm{s}$. The current distribution was uniform for all ramp rates and the deviation of the current in each strand was less than $7 \%$. Fig. 8 shows the current of each strand in the ninestrand cable with the ramp rate of $2 \mathrm{kA} / \mathrm{s}$.

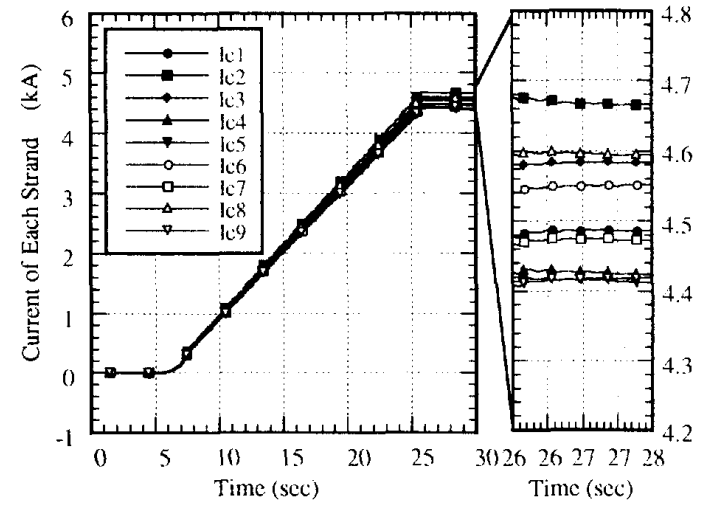

Fig. 8. Current distribution of the compacted nine-strand cable.

\section{E. Measurement of Heat Load}

The heat load to the full-scale model was measured with the forced flow condition of one-phase cold helium gas. The heat load to the innermost channel, where the superconducting cable was installed, was very small less than the measurable limit. The heat load to the outer shielding channel was measured to be $8.3 \mathrm{~W} / \mathrm{m}$ which was over two times larger than the design value $(3.5 \mathrm{~W} / \mathrm{m})$. The reason of the large heat load is under consideration. It is one possibility that some bending and twisted stress during the installation work remained in the bus line, and the multilayered super-insulators touched to the outermost corrugated tube. We are planning to carry out further measurements and improvement of the heat load of the bus-line.

\section{CONCLUSION}

Fabrication and installation of the full-scale model of the flexible superconducting bus-line were successfully carried out. Most parts of the superconducting bus-line were assembled in the factory. The assembled bus-line was then transported and installed at the experimental site.

The full-scale model was cooled down and excited successfully up to $40 \mathrm{kA}$ without a quench. The measured minimum propagation current was larger than $32.5 \mathrm{kA}$. Thus, the bus line was fully stabilized at the rated current of $30 \mathrm{kA}$. A specially developed aluminum stabilized $\mathrm{NbTi} / \mathrm{Cu}$ compacted strand cable was demonstrated to be sufficiently stable for the bus line. The measured current distribution of the nine-stand cable was quite uniform. Furthermore, the current transfer could occur locally from a strand becoming normal to other strands in superconducting state. This additionally enhanced the stability of the cable. The success of the full-scale model shows the feasibility and usefulness of flexible superconducting bus-lines for LHD and in other applications, too.

\section{REFERENCES}

11] O. Motojima K. Akaishi, K. Fujii, S. Fujiwara, S. Imagawa el al "Physics and engineering design on the Large Helical Device," Fusion Engineering and Design, Vol. 20, 1993, pp. 3-14.

(2) T. Milo, K. Takahala, S. Yamada, J. Yamamolo T. Uede and M. Ikeda. "Conceptual design and development of a superconducting bus-line for the Large Helical Device," Fusion Engineering and Design, Vol. 20, 1993, pp. 113-120. 